\title{
LA TERMOGRAFIA COMO AUXILIAR EN LA EUALUACIÓN HIGROTÉRMICA DE EDIFICIOS: EL CASO DEL EDIFICIO DE LA FACULTAD DE ARQUITECTURA DE LA UNNE
}

\author{
Herminia M. ALÍAS / Guillermo J. JACOBO / Pablo E. MARTINA / Juan J. CORACE \\ Herminia M. Alías. Cátedra Estructuras II. Área de la Tecnología y la Producción. Facultad de Arquitectura y Urbanismo (FAU). Universidad Nacional \\ del Nordeste (UNNE).Email: heralias@arq.unne.edu.ar. \\ Guillermo J. Jacobo. Cátedra Estructuras II. Área de la Tecnología y la Producción. Facultad de Arquitectura y Urbanismo (FAU). Universidad Nacio- \\ nal del Nordeste (UNNE). Email: gjjacobo@arq.unne.edu.ar. \\ Pablo E. Martina y Juan J. Corace. Grupo de Investigación y Desarrollo de Energías Renovables (GIDER). Depto. Termodinámica. Facultad de Inge- \\ niería (FI) - Universidad Nacional del Nordeste (UNNE). Email: pablo@ing.unne.edu.ar.
}

Palabras Clave: Termografía, evaluación higrotérmica, FAU - UNNE.

Keywords: Thermography, hygrothermal assessment, FAU - UNNE.

\section{RESUMEN}

Se comentan los resultados de la aplicación cualitativa de la termografía como complemento de una evaluación de desempeño higrotérmico - energético realizada en el edificio de la Facultad de Arquitectura y Urbanismo (FAU) de la Universidad Nacional del Nordeste (Campus UNNE de Resistencia, Chaco). Dicha evaluación consistió en mediciones de temperatura y humedad, contrastadas con simulaciones mediante software específico, en una muestra de aulas del edificio mencionado, durante períodos de verano y de invierno. En este contexto, se exponen las aplicaciones de la termografía como auxiliar en el proceso de la evaluación mencionada, especialmente en detección de puntos críticos (puentes térmicos, incidencia del asoleamiento y de los colores superficiales de las distintas superficies de la envolvente constructiva, entre otros).

\section{ABSTRACT}

The results of the qualitative application of thermography as a complement of a hygrothermal and energy performance evaluation in the building of the Faculty of Architecture and Urbanism (FAU) from the Universidad Nacional del Nordeste (UNNE), Resistencia, Chaco, are exposed here. This evaluation consisted of measurements of temperature and humidity, contrasted with simulations made by specific software in a sample of classrooms for periods of summer and winter.

In this context, applications of thermography are exposed as an aid in the process of that evaluation, especially in detection of critical points (thermal bridges, incidence of sunlight and the surface colors of the constructive envelope, between others). 


\section{INTRODUCCIÓN Y OBJETIVOS}

En el presente trabajo se exponen algunas aplicaciones cualitativas de la termografía en el proceso de evaluación del rendimiento higrotérmico-energético de un edificio concreto (el de la sede de la FAU - UNNE), en función del diseño tecnológicoconstructivo de su envolvente perimetral, como parte de una auditoría energética más amplia tendiente, en última instancia, a proponer pautas y medidas de mejoramiento para lograr el ahorro de energía eléctrica para climatización del edificio.

Ello se alcanzaría a partir de evaluaciones de desempeño mediante mediciones experimentales in situ, contrastadas con simulaciones dinámicas y con el aporte de las imágenes termográficas en la detección de problemas puntuales y zonas críticas. En el campus de la UNNE de la ciudad de Resistencia, Chaco (zona bioambiental "lb", muy cálida según IRAM 11603, 1996), y en el marco de un proyecto de investigación titulado "Evaluación térmico-energética de las sedes edilicias de las Facultades de Arquitectura y de Ingeniería de la UNNE", se está realizando actualmente en los edificios de las facultades de Arquitectura e Ingeniería, un análisis de las situaciones tecnológico-constructivas implementadas, así como de las condiciones de habitabilidad higrotérmica y de consumo energético de los que dichas situaciones son responsables, mediante el empleo de programas de simulación dinámica, validados con mediciones experimentales y un diagnóstico auxiliar por termografía.

El objetivo es elaborar un diagnóstico de situación, para proponer, criterios de optimización tendientes a lograr una reducción del consumo anual de electricidad, sin disminuir las condiciones de habitabilidad de los espacios interiores. Ello representaría una instancia inicial dentro de un proceso de generación de las bases de políticas institucionales en la UNNE tendientes al URE en la edificación (ALÍAS ET AL., 2011).

\section{La termografía: fundamentos conceptuales}

La termografía infrarroja es un método no destructivo que permite determinar la distribución superficial de la temperatura del área para analizar. Utilizada en conjunto con las técnicas tradicionales de monitoreo de edificios, se convierte en una valiosa herramienta para detectar defectos en la envolvente de los edificios, puentes térmicos, infiltraciones de aire y humedad (BALARAS Y ARGIRIOU, 2002; en FLORES LARSEN Y HONGN, 2012). Esta técnica, como complemento de las auditorías térmico-energéticas, es particularmente importante para evaluar el confort térmico a través de la medición de temperaturas superficiales de muros, pisos y techos.

Los procesadores térmicos de imágenes (figura 1) son cámaras manuales de procesamiento de imágenes que se utilizan para el mantenimiento predictivo, la solución de problemas en equipos y la verificación. Producen imágenes térmicas y visuales en una pantalla de $640 \times 480$ de resolución. El procesador térmico de imágenes puede guardar la imagen como una simple fotografía o como una imagen radiométrica que permite un ulterior análisis de la temperatura.

El rango de temperaturas de las imágenes térmicas comienza a $-20^{\circ} \mathrm{C}$, y aumenta hasta $+250^{\circ} \mathrm{C}$ (para el modelo que se utilizó: procesador térmico de imágenes marca FLUKE Ti9).

Conceptualmente, un procesador térmico de imágenes se basa en el principio según el cual todos los objetos con temperaturas mayores al cero absoluto emiten energía en forma radiación infrarroja (comprendida en la banda entre $0,75 \pi \mathrm{m}$ a $1000 \pi m$, fuera del rango del ojo humano, que detecta longitudes de onda entre 0,4 y $0,7 \pi \mathrm{m}$.). Una cámara termográfica es un dispositivo capaz de formar imágenes visibles a partir del el espectro electromagnético infrarrojo medio. Opera con 
Fig. 1: cámara termográfica. Fuente: http://es.rs-online.com/ web/generalDisplay.html?id=termo\&file=ti10-25

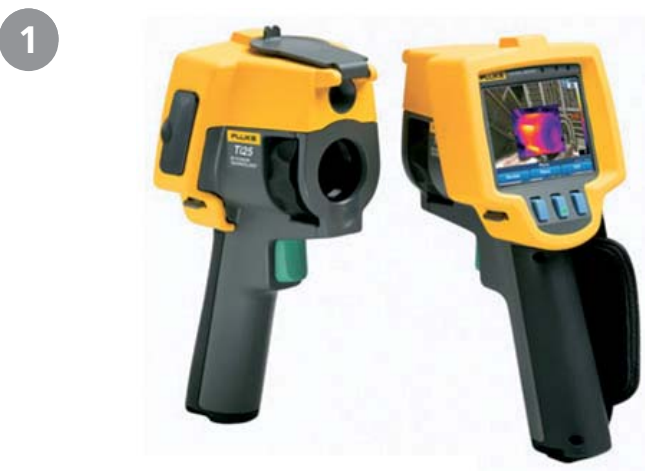

longitudes de onda en la zona del infrarrojo térmico, que se considera entre $3 \mu \mathrm{m}$ y $14 \mu \mathrm{m}$. En otros términos, la cámara termográfica percibe la radiación infrarroja emitida de los cuerpos detectados y que la transforma en imágenes luminosas para ser visualizada por el ojo humano. (figura1).

La cantidad de energía irradiada se basa en dos factores principales: la temperatura de la superficie del objeto y la emisividad de dicha superficie (la capacidad de un objeto de emitir radiación comparado con un cuerpo negro: 1 es un emisor perfecto y 0 un reflector perfecto. También depende de la temperatura del cuerpo).

El procesador térmico de imágenes detecta la energía infrarroja proveniente de un objeto y utiliza esta información para estimar la temperatura de dicho objeto. La mayoría de los objetos medidos tales como metal pintado, madera, agua, piel y tela son muy eficientes para irradiar energía, y es muy fácil obtener mediciones muy exactas.

Para superficies que son eficientes para irradiar energía (alta emisividad), el factor de emisividad se estima en un $95 \%(00,95)$. Este valor estimativo funciona para la mayoría de los propósitos. Sin embargo, esta simplificación no funciona para superficies brillantes o metales sin pintar. Estos materiales no son eficientes para irradiar energía y están clasificados como de baja emisividad. Para medir con exactitud materiales con baja emisividad, es necesaria una corrección de emisividad (FLUKE, 2010).

Existen varios métodos para determinar la emisividad de una superficie, siendo el más extendido el de medir la temperatura de la superficie con un termómetro calibrado y ajustar la emisividad de la cámara hasta que ambas temperaturas coincidan (FLORES LARSEN y HONGN, Óp. cit., 2012). EI método más sencillo de corrección es configurar el
Fig. 2. Las cámaras termográficas miden la temperatura superficial del vidrio, no lo que se visualiza por detrás de él, pues la radiación infrarroja no lo atraviesa. Fuente: fotografías propias del edificio de la FAU - UNNE. Fuente: imágenes termográficas y fotografías propias
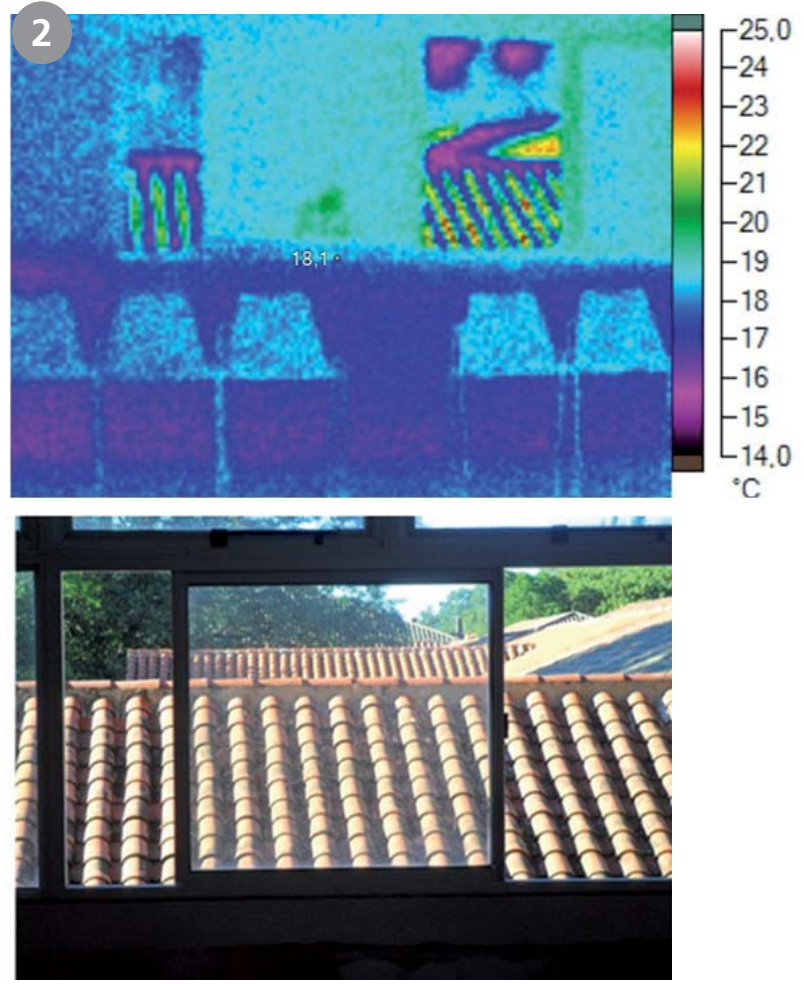

procesador térmico de imágenes al valor correcto de emisividad para que calcule automáticamente la temperatura correcta de la superficie. Si el procesador térmico de imágenes utiliza un valor fijo de emisividad (lo que significa que se configura en un valor y el usuario no puede ajustarlo), entonces la medición del procesador térmico de imágenes deberá multiplicarse por un valor encontrado en la tabla de búsqueda para obtener una estimación más exacta de la temperatura real. El modelo que se utilizó en este caso (Ti9) tiene una emisividad que se fija de manera permanente en 0,95 , lo cual funciona bien para la mayoría de las superficies, pero puede proporcionar una lectura muy inexacta si se utiliza directamente sobre una superficie metálica brillante. Otros factores para tener en cuenta cuando se trabaja con termografía incluyen: a) el conocimiento de la radiación térmica proveniente de los alrededores del objeto y que es reflejada por este (es por ello que las imágenes termográficas de objetos en el exterior suelen tomarse entrada la noche o a las primeras horas de la mañana, para que la incidencia de la radiación del entorno sea la menor posible: se minimiza la radiación de objetos urbanos calientes que se enfrían durante la noche); b) que el objeto debe estar ubicado en un ángulo correcto en relación con la cámara, de preferencia frente a esta, ya que la emisividad es una propiedad óptica que depende del ángulo de incidencia y c) que el vidrio es impermeable a los infrarrojos, por lo tanto, se mide la temperatura superficial del vidrio, no lo que está por detrás (figura 2). 
Figura 3: Fotos satelitales del Campus de la UNNE, Resistencia (arriba, izquierda) y el edificio de la Facultad de Arquitectura -FAU- (arriba, derecha). Perspectiva del edificio de la FAU (derecha): sector antiguo u original (cubierta de tejas) y sector nuevo, bloque de "talleres" (al fondo, el bloque de tres niveles). Fuente: elaboración propia a partir de imágenes satelitales de "Google Earth"
Figura 4: Resoluciones constructivas del sector antiguo del edificio de la FAU - UNNE: techos de tejas coloniales sobre estructura de madera y cielorraso independiente a la cal y muros de ladrillos macizos comunes de $30 \mathrm{~cm}$. revocados. Fuente: ALÍAS ET AL., 2011

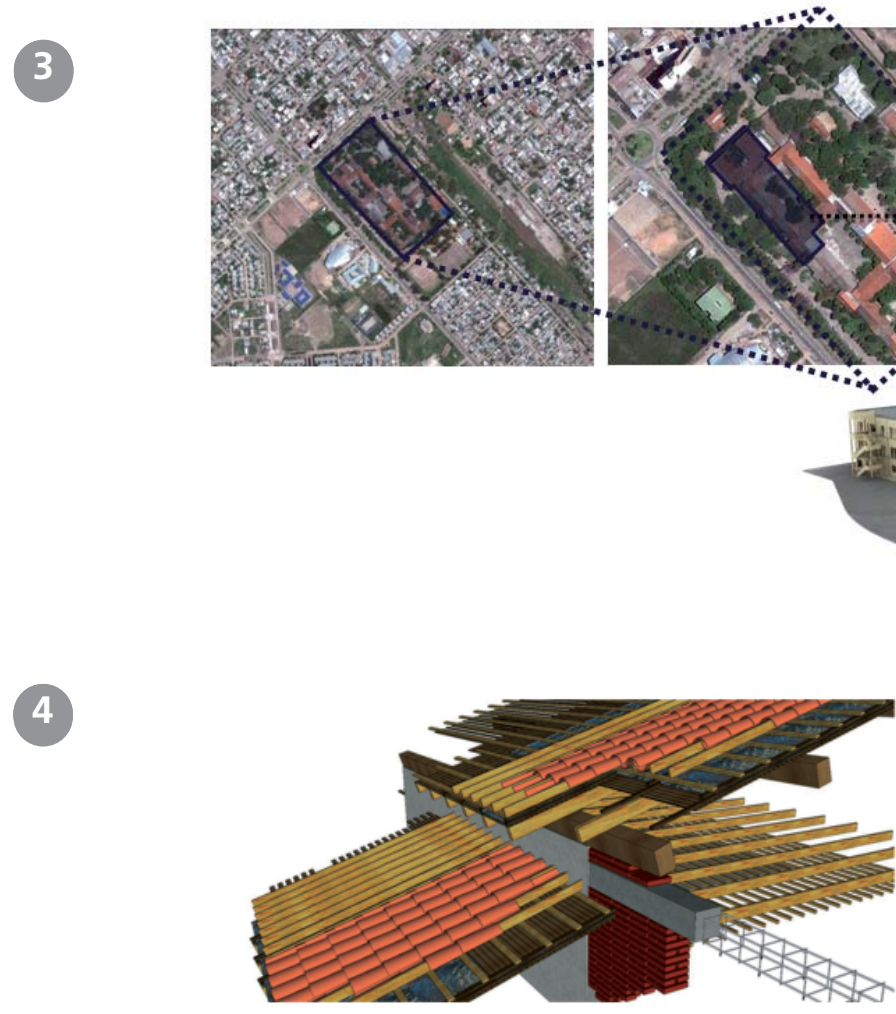

UNIVERSIDADNACIONAL DEL NORDESTE-CAMPUS RESISTENCIA
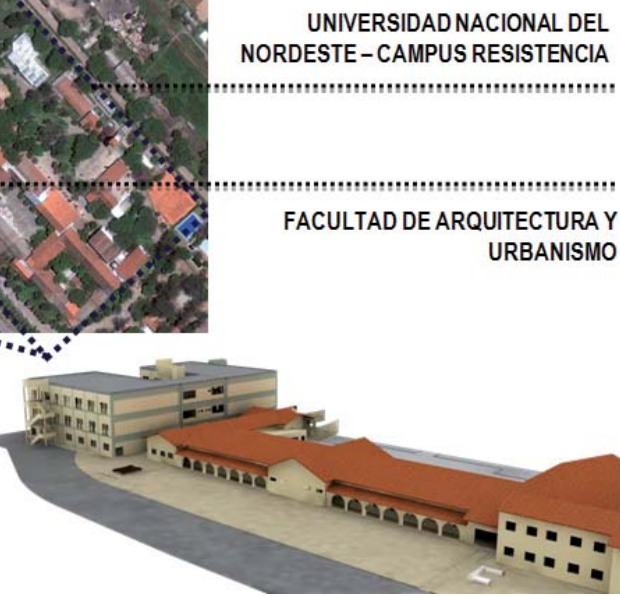

Las aplicaciones de los procesadores térmicos de imágenes incluyen: militares y policiales para detección de objetivos y adquisición de datos; seguridad y antiterrorismo; mantenimiento predictivo (detección temprana de fallos tanto mecánicos como eléctricos); control de procesos; detección o análisis de incendios; industria automotriz; inspección de suelos; auditoría de aislantes acústicos; inspección de muros; medicina y diagnosis; análisis no destructivos; test de calidad en entornos de producción; detección de polución; detección de temperatura corporal (controles ante epidemia de Gripe A, por ejemplo).

\section{El edificio de la Facultad de Arquitectura de la UNNE}

El edificio de la Facultad de Arquitectura y Urbanismo (FAU) de la UNNE, implantado en el Campus Universitario de Av. Las Heras (figura 3), en el sector centro-sur de la ciudad de Resistencia, Chaco, se erigió originalmente a fines de la década de 1950 como un hogar-escuela y en 1957 se convirtió en la sede universitaria de la UNNE. Fue construido con características formales y tecnológico-constructivas similares a las de otros edificios institucionales implantados en distintas regiones y provincias del país (Salta, Mendoza, Corrientes, Buenos Aires, etc.), respondiendo a tipologías proyectuales prototípicas, por lo que, como caso de estudio, representa un universo más amplio (ALÍAS ET AL., 2011). (Figura 3: Fotos satelitales del Campus de la UNNE, Resistencia (arriba, izquierda) y el edificio de la Facultad de Arquitectura -FAU- (arriba, derecha). Perspectiva del edificio de la FAU (derecha): sector antiguo u original (cubierta de tejas) y sector nuevo, bloque de "talleres" (al fondo, el bloque de tres niveles). Fuente: elaboración propia a partir de imágenes satelitales de "Google Earth").

En cuanto a su tecnología constructiva, el edificio presenta dos sectores muy diferentes:

1. Un sector "original" o "antiguo", resuelto mediante técnicas artesanales tradicionales: muros de mampuestos comunes macizos de 0,30 m. de espesor, revocados exterior e interiormente y cubiertas de tejas cerámicas tipo coloniales sobre estructura de madera. (Figura 4: Resoluciones constructivas del sector antiguo del edificio de la FAU - UNNE: techos de tejas coloniales sobre estructura de madera y cielorraso independiente a la cal y muros de ladrillos macizos comunes de $30 \mathrm{~cm}$. revocados. Fuente: ALÍAS ET AL., 2011).

2. Un sector "nuevo", anexado en la década del 90 (consiste en dos bloques de tres niveles cada uno, unidos por un bloque principal -hall y conector-), resuelto mediante estructuras portantes prefabricadas de hormigón armado, muros dobles con cámara de aire y muros de múltiples ca- 
Figura 5: Resoluciones constructivas del sector nuevo del edificio de la FAU - UNNE: muros compuestos de ladrillos huecos de $8 \times 18 \times 33 \mathrm{~cm}$ al exterior, cámara de aire y ladrillos comunes macizos de 0,18 $\mathrm{m}$ de espesor al interior (arriba, izquierda). Estructuras portantes prefabricadas de hormigón armado. Entrepisos (arriba, derecha) y azoteas accesibles (abajo) de $\mathrm{H}^{\circ} \mathrm{A}^{\circ}$. Fuente: ALÍAS ET AL., 2011
6. Tabla I: Algunos parámetros tecnológicos e higrotérmicos de las envolventes del edificio de la FAU - UNNE. Fuente: ALÍAS ET AL., 2011)
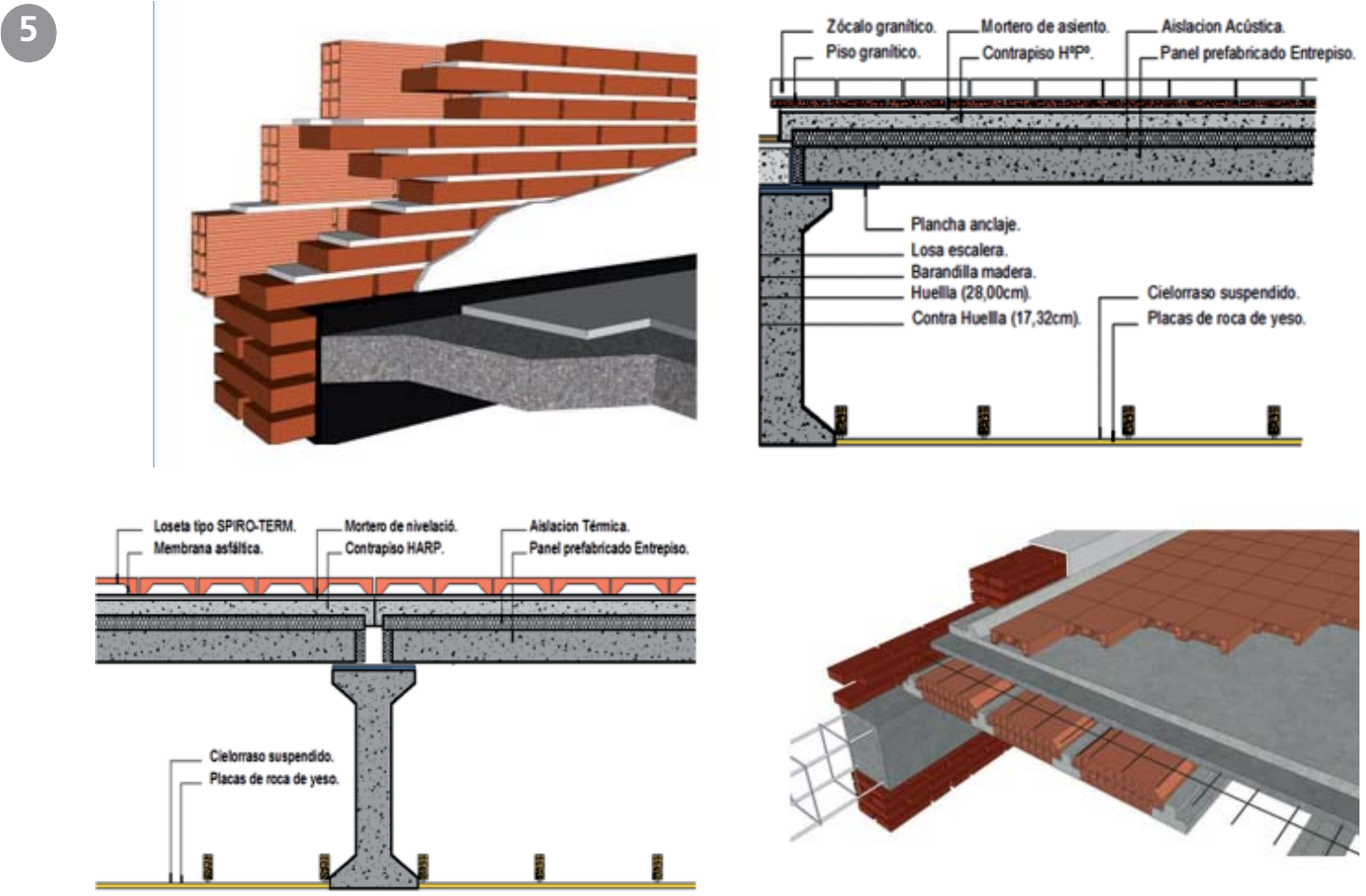

\begin{tabular}{|c|c|c|c|c|c|c|c|c|c|c|c|}
\hline Zonas & $\begin{array}{l}\text { Muros } \\
\text { exteriores }\end{array}$ & $\begin{array}{l}\text { Transm. } \\
\text { Térmica } \\
\text { (W/m2 } \\
\mathrm{K})\end{array}$ & $\begin{array}{l}\text { Esta- } \\
\text { ción }\end{array}$ & $\begin{array}{l}\text { Categoría } \\
\text { (s/RAM } \\
11605)\end{array}$ & Techos & $\begin{array}{l}\text { Transm. } \\
\text { Térmica } \\
(\mathrm{W} / \mathrm{m} 2 \\
\mathrm{K})\end{array}$ & Estación & $\begin{array}{l}\text { Categoría } \\
\text { (s/lRAM } \\
11605 \text { ) }\end{array}$ & Carpinterías & $\begin{array}{l}\text { Transm. Térmica } \\
(\mathrm{W} / \mathrm{m} 2 \mathrm{~K})\end{array}$ & $\begin{array}{l}\text { Categoría } \\
\text { (s/RAM } \\
11507-4)\end{array}$ \\
\hline \multirow[t]{2}{*}{$\begin{array}{l}\text { Sector } \\
\text { antiguo } \\
\text { (origi- } \\
\text { nal) }\end{array}$} & \multirow{2}{*}{$\begin{array}{l}\text { Ladr. } \\
\text { comunes } \\
(\mathrm{e}=0,30 \mathrm{~m}) \text {, } \\
\text { c/revoque } \\
\text { en ambas } \\
\text { caras }\end{array}$} & \multirow[t]{2}{*}{1,87} & Verano & "C" (mín.) & \multirow[t]{2}{*}{$\begin{array}{l}\text { Tejas colonia- } \\
\text { les s/estruct. } \\
\text { madera. Cielo- } \\
\text { rraso indep. a } \\
\text { la cal. }\end{array}$} & 0,94 & Verano & $\begin{array}{l}\text { No clasifica } \\
(K>0,72)\end{array}$ & \multirow{2}{*}{$\begin{array}{l}\text { De } 3 \text { hojas de } \\
\text { abrir, c/ vidrio } \\
\text { simple 4mm. } \\
\text { Marcos de chapa } \\
\text { №18, c/posti- } \\
\text { gones madera } \\
\text { semidura. }\end{array}$} & \multirow[t]{2}{*}{5,98} & \multirow[t]{2}{*}{$\begin{array}{l}\text { No clasificable } \\
(K>4)\end{array}$} \\
\hline & & & $\begin{array}{l}\text { Invier- } \\
\text { no }\end{array}$ & $\begin{array}{l}\text { No } \\
\text { clasifica } \\
(K>1,85)\end{array}$ & & 1,08 & Invierno & $\begin{array}{l}\text { No clasifica } \\
(\mathrm{K}>1,00)\end{array}$ & & & \\
\hline \multirow{3}{*}{\begin{tabular}{|l|} 
Sector \\
nuevo \\
(am- \\
plia- \\
ción)
\end{tabular}} & \multirow{3}{*}{$\begin{array}{l}0,96 \text { Ladr. } \\
\text { huecos } \\
\text { +Ladr. } \\
\text { comunes } \\
\mathrm{e}=0,18 \mathrm{~m} \text {. }\end{array}$} & \multirow[t]{3}{*}{0,96} & \multirow[t]{3}{*}{ Verano } & \multirow{3}{*}{$\begin{array}{l}\text { "C" } \\
\text { (mín.) }\end{array}$} & \multirow{2}{*}{$\begin{array}{l}\text { Azotea } \\
\text { accesible losa } \\
H^{\circ} A^{\circ}\end{array}$} & 0,50 & Verano & "C" (mín.) & \multirow{3}{*}{$\begin{array}{l}\text { Marcos y hojas } \\
\text { de chapa №16 } \\
\text { y vidrio simple } \\
4 m m \text { repartido } \\
\text { en hojas. }\end{array}$} & \multirow[t]{3}{*}{6,00} & \multirow{3}{*}{$\begin{array}{l}\text { No clasificable } \\
(\mathrm{K}>4)\end{array}$} \\
\hline & & & & & & 0,51 & Invierno & "B" (med.) & & & \\
\hline & & & & & $\begin{array}{l}\text { Entrepiso losa } \\
H^{\circ} A^{\circ}\end{array}$ & & & & & & \\
\hline
\end{tabular}

pas, para los diferentes niveles. (Figura 5: Resoluciones constructivas del sector nuevo del edificio de la FAU - UNNE: muros compuestos de ladrillos huecos de $8 \times 18 \times 33 \mathrm{~cm}$ al exterior, cámara de aire y ladrillos comunes macizos de 0,18 m de espesor al interior (arriba, izquierda). Estructuras portantes prefabricadas de hormigón armado. Entrepisos (arriba, derecha) y azoteas accesibles (abajo) de $H^{\circ} A^{\circ}$. Fuente: ALÍAS ET AL., 2011).

\section{MATERIALES Y MÉTODOS}

En trabajos previos se realizó un análisis funcional, espacial y técnico-constructivo del edificio, que permitió definir diferentes paquetes de locales y sectores, agrupando funciones, patrones de ocupación y tecnologías constructivas homogéneas (CORONEL ET ÁL., 2011). A partir de dicha zonificación básica se definió una muestra de locales representativos de las diferentes zonas, quedando determinado que los monitoreos térmicos se realizarían en las seis aulas del edificio (dos de ellas pertenecientes al sector antiguo y cuatro ubicadas en el bloque nuevo, en sus diferentes niveles). (Tabla l: Algunos parámetros tecnológicos e higrotérmicos de las envolventes del edificio de la FAU - UNNE. Fuente: ALIAS ET AL., 2011)

El monitoreo térmico invernal de la muestra definida de locales se realizó durante el período com- 
7. Tabla II: Algunas especificaciones del procesador térmico de imágenes utilizado (FLUKE Ti9). Fuente: FLUKE, 2010

Rango de temperatura (no calibrada por debajo de $-10^{\circ} \mathrm{C}$ ) de $-20^{\circ} \mathrm{C}$ a $+250^{\circ} \mathrm{C}$

Precisión........................................

Campo de visión...........................................................2 $23^{\circ} \times 17^{\circ}$

Distancia mínima de enfoque lente térmica....................15 cm (aprox. 6 pulg.)

Tipo de detector.............................................Arreglo de plano focal de $160 \times 120$ microbolómetro sin enfriamiento

Tipo de lente infrarrojo.......

$20 \mathrm{~mm} \mathrm{EFL}$, lente $\mathrm{F} / 0,8$

Sensibilidad térmica (DTER)

$\leq 0,2^{\circ} \mathrm{C}$ a $30^{\circ} \mathrm{C}(200 \mathrm{mK})$

Banda espectral infrarroja

$7,5 \mu \mathrm{m}$ a $14 \mu \mathrm{m}$

prendido entre el 30 de junio y el 14 de julio de 2011, las veinticuatro horas de cada día. Las aulas estuvieron en condiciones de uso normal durante el monitoreo. Por su parte, el monitoreo térmico estival se realizó en el período comprendido entre el 8 y el 23 de marzo de 2012, las veinticuatro horas de cada día. Las aulas estuvieron en condiciones de uso normal durante el monitoreo. Para los mismos períodos monitoreados, se realizaron simulaciones dinámicas de desempeño higrotérmico del edificio mediante el programa ECOTECT.

Asimismo, se aplicaron las verificaciones higrotérmicas (según normas IRAM 11601, 11605, 11625, $11630,11507-1$ y $11507-4$ ) a los componentes de las envolventes (muros y techos) de los locales de la muestra definida, y se obtuvieron los resultados que se exponen en la tabla I.

\section{Imágenes termográficas de la envolvente construc- tiva del edificio}

Como complemento de las verificaciones según normativa y las simulaciones dinámicas de los desempeños higrotérmicos y energéticos de las zonas del edificio (validadas mediante las mediciones in situ de temperaturas y humedades en las mismas zonas), se tomaron registros térmicos de las superficies de las envolventes constructivas del edificio mediante termografía. Para ello, la metodología consistió en tomar imágenes termográficas de diferentes sectores del edificio bajo análisis, seleccionándose algunas de las zonas más representativas, tanto del sector original como del bloque nuevo. Se utilizó una cámara termográfica marca Fluke, modelo Ti9. 7.(Tabla II).

Se seleccionaron las imágenes más representativas de las situaciones detectadas en cada caso y se complementaron las imágenes térmicas con imágenes visibles. Asimismo, fue necesario considerar el entorno del edificio de la FAU (para detectar fuentes calientes o posibles causas de reflejos), así como la emisividad de las superficies y objetos registrados en cada imagen termográfica tomada, para detectar la posible existencia en simultáneo de superficies con emisividades muy diferentes.

Por último, si bien por un lado es recomendable realizar la toma de imágenes termográficas de exteriores de edificios por la noche o inmediatamente antes de la salida del sol para que la incidencia de la radiación del entorno sea la menor posible, para este caso particular se decidió considerar las situaciones y procesos reales que ocurren durante las horas de ocupación edilicia efectiva y las influencias a las cuales el edificio está expuesto cotidianamente, debido a que más que los datos cuantitativos de las temperaturas superficiales de la envolvente edilicia, interesaron los aspectos cualitativos referidos, por ejemplo, a la incidencia de la radiación solar en las distintas zonas y materiales y la respuesta de la envolvente del edificio frente a este factor. La toma de imágenes, tanto exteriores como interiores, se realizó en dos momentos: durante la tarde del día 24 de abril de 2012 (la temperatura exterior osciló entre 19 y $25^{\circ}$ C) y durante la mañana del día 03 de julio de 2013 (la temperatura exterior osciló entre 15 y $19^{\circ} \mathrm{C}$ ).

En la siguiente serie de imágenes termográficas obtenidas, se exponen y analizan las características, particularidades, factores incidentes y respuestas detectados en diferentes sectores de la envolvente constructiva (techos, pisos y muros) del edificio bajo análisis.

\section{Abril de 2012}

Se detectan importantes heterogeneidades (puentes térmicos) en la envolvente del bloque edilicio nuevo, constituidas por la estructura de columnas y vigas prefabricadas de importantes secciones de $\mathrm{H}^{\circ} \mathrm{A}^{\circ}$ (figs. 6 - 7 - 8 y $14-15$ - 17). El asoleamiento acentúa aún más la diferencia térmica (de hasta 
Fig. 6. Superficies exteriores de muros del bloque nuevo de edificio de la FAU el 24/04/2012 a las 16,14 hs. Fuente: imágenes termográficas y fotografías propias

Fig. 7. Superficies exteriores de muros del bloque nuevo del edificio de la FAU el 24/04/2012 a las 16,15 hs. Fuente: imágenes termográficas y fotografías propias

Fig. 8. Superficies exteriores de muros del bloque nuevo del edificio de la FAU el 24/04/2012 a las 16,21 hs. Fuente: imágenes termográficas y fotografías propias

Fig. 9. Superficies exteriores de techos del sector antiguo del edificio de la FAU el 24/04/2012 a las 16,30 hs. Fuente: imágenes termográficas y fotografías propias
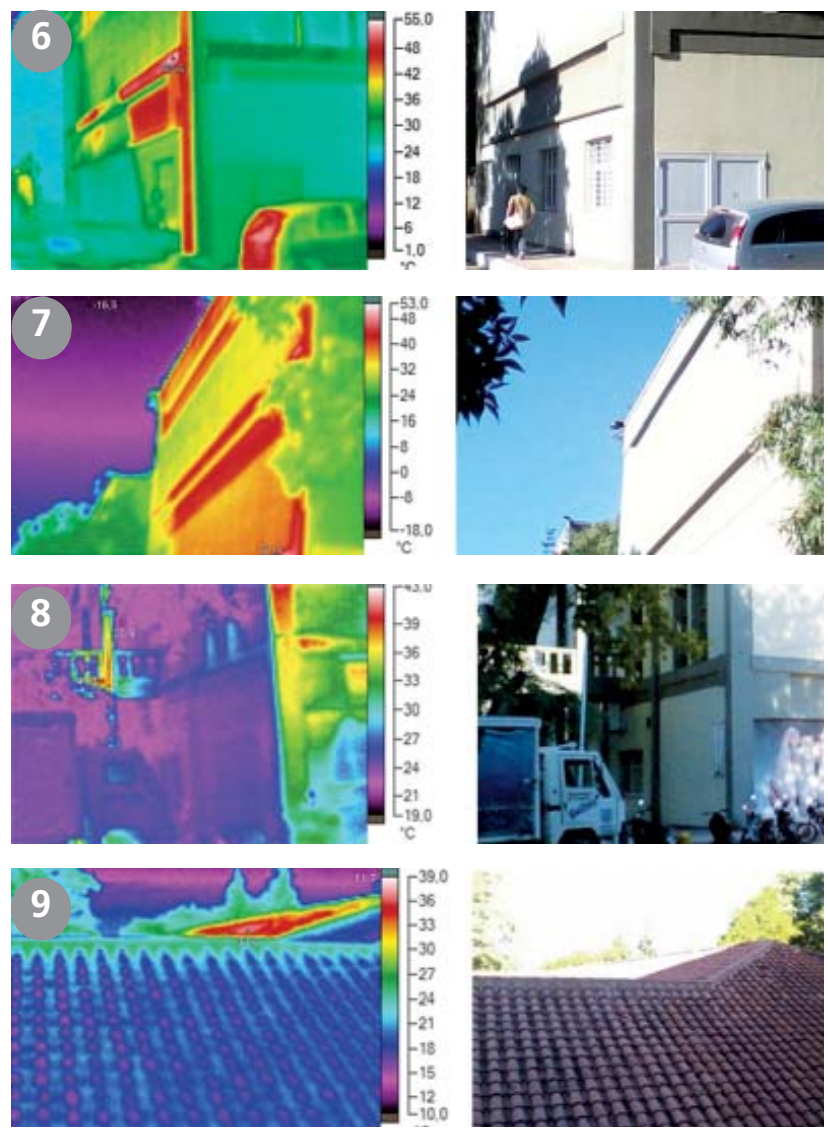

$17^{\circ} \mathrm{C}$ ) entre la superficie del muro de cerramiento y la superficie expuesta de los puentes térmicos de $\mathrm{H}^{\circ} \mathrm{A}^{\circ}$. En la situación no expuesta al sol, la diferencia térmica se reduce a $9 \circ 10^{\circ} \mathrm{C}$.

Las superficies expuestas de la envolvente que reciben radiación solar en algún momento del día se mantienen a temperaturas, según la figura 8 , de aproximadamente $10^{\circ} \mathrm{C}$ por encima de las superficies más protegidas (por vegetación o por sombras permanentes de los volúmenes circundantes), que casi no están expuestas al asoleamiento. 8-11 (Fig. 6, Fig. 7, Fig. 8, Fig. 9).

Lo mismo se expone en las figuras 9 y 19, en las que se visualiza la gran influencia que ejerce la exposición a la radiación solar en las superficies de los techos (las porciones asoleadas en la fig. 9 se encuentran a $37^{\circ} \mathrm{C}$ aproximadamente, y las que están en sombra presentan entre 13 y $21^{\circ} \mathrm{C}$ en el horario de registro, en ambas figuras, aunque corresponden a un techo de tejas y a una azotea re-
Fig. 10. Superficies exteriores de muros del bloque nuevo del edificio de la FAU el 24/04/2012 a las 16,19 hs. Fuente: imágenes termográficas y fotografías propias

Fig. 11. Interior de un aula - taller de P.B. del sector nuevo del edificio de la FAU, el 24/04/2012 a las 16,23 hs. Fuente: imágenes termográficas y fotografías propias

Fig. 12. Exteriores del Aula 6, del sector antiguo del edificio de la FAU, el 24/04/2012 a las 16,30 hs. Fuente: imágenes termográficas y fotografías propias

Fig. 13. Interior del Aula 6, del sector antiguo del edificio de la FAU, el 24/04/2012 a las 16,43 hs. Fuente: imágenes termográficas y fotografías propias.
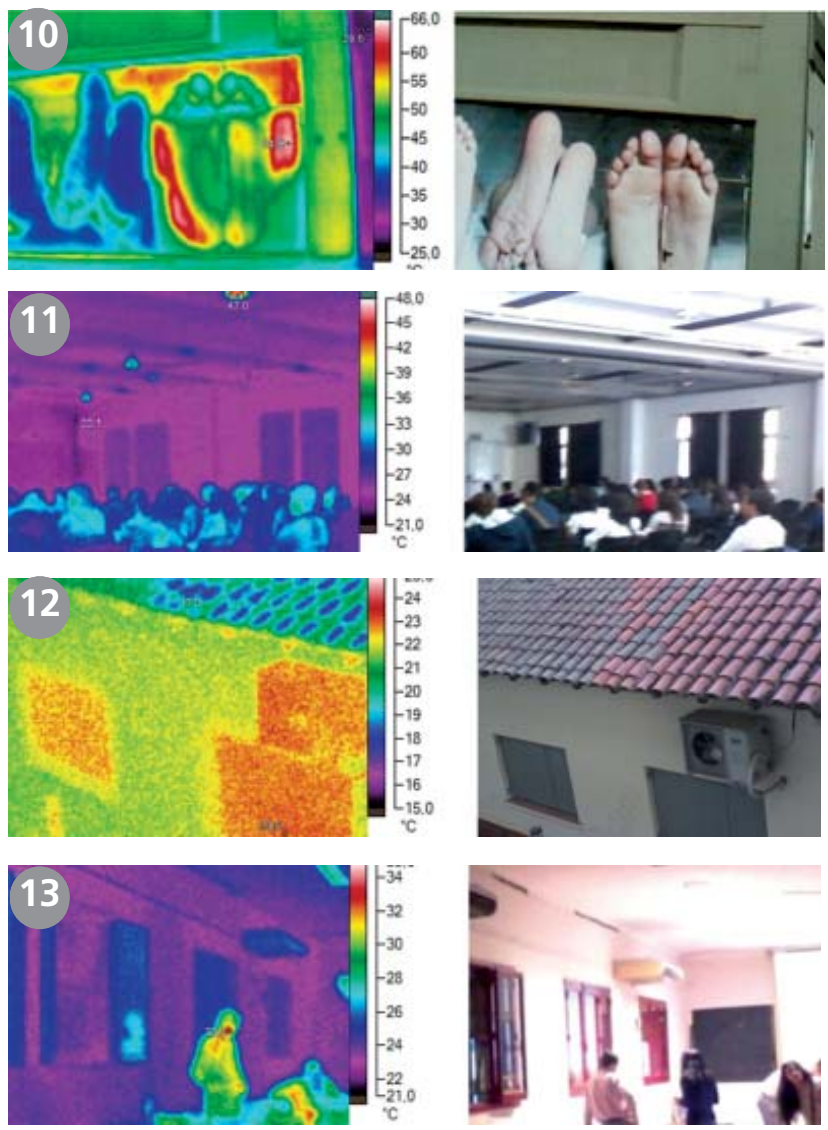

vestida con losetas cerámicas, respectivamente, y a diferentes días de toma de la imagen).

Los colores de las superficies revisten importancia en la respuesta térmica de la superficie de que se trate. En la fig. 10 se hacen evidentes las sustanciales diferencias térmicas que se obtienen en superficies muy cercanas entre sí, debido únicamente a un diferente color de dichas superficies (siendo la composición del muro idéntica bajo la capa de pintura). 12-15 (Fig. 10, Fig. 11, Fig. 12, Fig. 13).

En los espacios interiores registrados del sector nuevo, como el del aula que se muestra en la figura 11, se advierten temperaturas superficiales un poco mayores ( $2 \circ 3^{\circ} \mathrm{C}$ más) en los muros respecto de los entrepisos y vigas de $\mathrm{H}^{\circ} \mathrm{A}^{\circ}$, (para este día de abril de 2012). La incidencia de la radiación solar en el exterior de estas superficies murarias (en el momento del registro) sin duda ejerce influencia significativa en este caso. 
Fig. 14. Superficies exteriores de muros del bloque nuevo del edificio de la FAU, el 03/07/2013 a las 09,16 hs. Fuente: imágenes termográficas y fotografías propias

Fig. 15. Superficies exteriores de muros del bloque nuevo del edificio de la FAU, el 03/07/2013 a las 09,01 hs. Fuente: imágenes termográficas y fotografías propias.

Fig. 16. Superficies exteriores del sector antiguo del edificio de la FAU, el 03/07/2013 a las 09,43 hs. Fuente: imágenes termográficas y fotografías propias
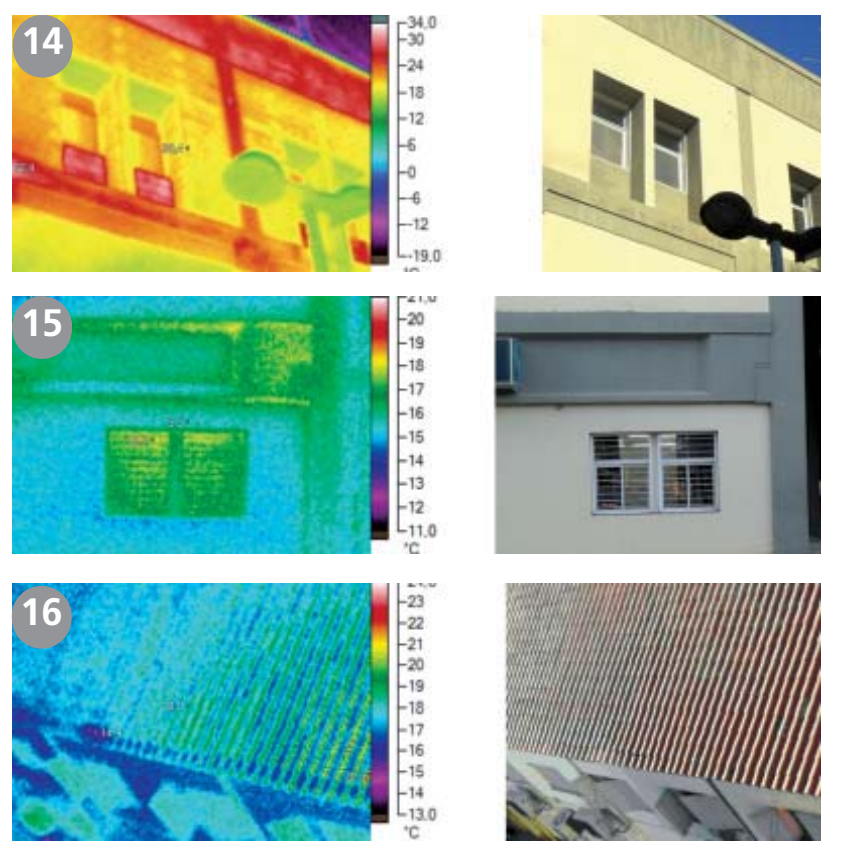

La misma situación se registra en el sector antiguo, que se muestra exterior e interiormente en las figuras 12-16 y 13, respectivamente: los techos presentan menores temperaturas $\left(18\right.$ a $19^{\circ} \mathrm{C}$ en el exterior, y $22^{\circ} \mathrm{C}$ en promedio en el interior) respecto de los muros (que se mantienen en el orden de 20 a $22^{\circ}$ C aprox.). El caso de las figs. 12 y 13 corresponde a un sector edilicio no expuesto directamente a la radiación solar durante buena parte del día, por lo que las temperaturas superficiales registradas se deben casi exclusivamente a la constitución material de las superficies. Los dispositivos de protección de las carpinterías (de madera), en este caso presentan mayores temperaturas que el resto de la envolvente.

\section{Julio de 2013}

En la azotea inaccesible del bloque edilicio nuevo, revestida con losetas cerámicas huecas (denominadas comercialmente "térmicas"), las discontinuidades o puentes térmicos están representados por los canales de desagües pluviales (figura 18), que en el caso del registro de julio de 2013 presentan menores temperaturas $\left(16^{\circ} \mathrm{C}\right.$ aprox.) que el resto de la superficie de la azotea ( $22^{\circ} \mathrm{C}$ en promedio aprox.). 16-21 (Fig. 14, Fig. 15, Fig. 16, Fig. 17, Fig. 18, Fig. 19).

\section{RESULTADOS OBTENIDOS}

Por un lado, según verificaciones mediante la nor-
Fig. 17. Parte de las azoteas del sector nuevo del edificio de la FAU, el 03/07/2013 a las 09,44 hs. Fuente: imágenes termográficas y fotografías propias

Fig. 18. Parte de las azoteas del sector nuevo del edificio de la FAU, el 03/07/2013 a las 09,44 hs. Fuente: imágenes termográficas y fotografías propias

Fig. 19. Parte de las azoteas del sector nuevo del edificio de la FAU, el 03/07/2013 a las 09,46 hs. Fuente: imágenes termográficas y fotografías propias
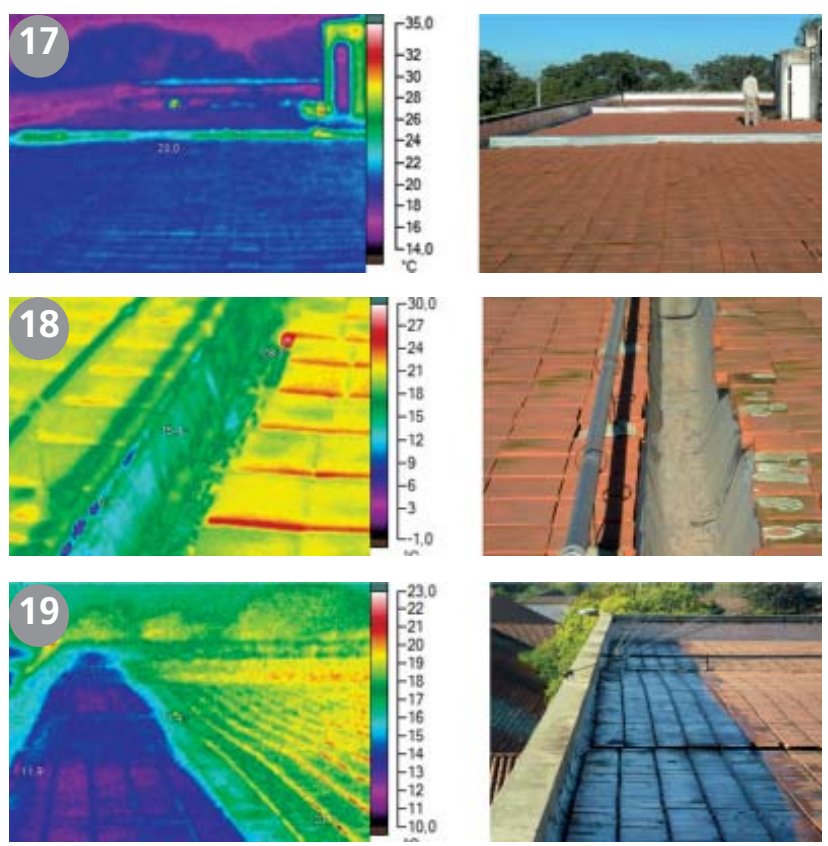

mativa de habitabilidad vigente se verificaron: 1) una baja resistencia térmica de la envolvente en general, especialmente del bloque nuevo; 2) puentes térmicos importantes en muros y techos del sector "nuevo" (la estructura de $\mathrm{H}^{\circ} \mathrm{A}^{\circ}$ —vigas y columnas prefabricadas de grandes secciones- representa heterogeneidades cuyo valor de transmitancia térmica supera ampliamente el $50 \%$ del valor de transmitancia de la envolvente opaca, lo que representa malas condiciones, según IRAM 11605:96) y 3) puntos críticos en cuanto al estado y modalidad de uso de las carpinterías: las carpinterías del sector "nuevo" se hallan en situación de alta exposición a agentes exteriores —en su mayoría no cuentan con protección-, en tanto que las carpinterías del sector "antiguo", aunque cuentan con dispositivos de protección, presentan patologías debido al agotamiento de vida útil -desprendimientos de material de marcos y hojas, fisuras perimetrales en el vano-, que generan importantes cargas térmicas.

Por otro lado, según las simulaciones de comportamiento higrotérmico de aulas y según el monitoreo de desempeño térmico de las mismas aulas, se detectó que 1) en invierno, temperaturas interiores que, durante el $65 \%$ del período de registro -30 de junio al 14 de julio de 2011 - se hallaron por debajo del límite inferior de la franja de confort regional definida $\left(19^{\circ} \mathrm{C} / 29^{\circ} \mathrm{C}\right)$; además, se detectaron situaciones derivadas de un mal uso de los locales, como la apertura permanente de ven- 
tanas (aun en horas nocturnas de muy bajas temperaturas; 2) en verano, temperaturas interiores que, durante el $95 \%$ del período de registro -08 al 23 de marzo de 2012 - se hallaron por encima del límite superior de la franja de confort regional definida $\left(19^{\circ} \mathrm{C} / 29^{\circ} \mathrm{C}\right)$. También se detectaron situaciones derivadas de un desconocimiento de las ventajas de una ventilación selectiva, como la apertura permanente de ventanas, aun en horas del mediodía y la siesta, cuando las temperaturas externas experimentan los picos máximos.

Por último, los registros obtenidos mediante termografía complementan los resultados arrojados por las otras instancias procedimentales aplicadas, detectándose algunos factores que podrían estar incidiendo altamente en el desempeño térmico regular a deficiente registrado (ALÍAS ET AL., 2011) mediante los otros procedimientos desarrollados:

1) importantes diferencias térmicas entre las superficies de una misma pared o techo, según su material constitutivo básico (en este sentido las estructuras de $\mathrm{H}^{\circ} \mathrm{A}^{\circ}$ del sector nuevo, por ejemplo, presentan temperaturas de entre 15 y $18^{\circ} \mathrm{C}$-expuestas al sol- mayores que las superficies adyacentes de mampostería revocada, con el riesgo de patologías - por ejemplo, las asociadas a condensaciones superficiales que estas diferencias térmicas pueden generar-);

2) importantes diferencias térmicas entre las superficies de una misma pared según su color superficial —variaciones de emisividad y de coeficiente de absorción- (pinturas de diferentes colores registran temperaturas diferentes, incluso entre superficies adyacentes muy próximas) y

3) Importantes diferencias térmicas entre superficies según su grado de asoleamiento (la incidencia de la radiación solar en las superficies es responsable del aumento de temperatura de estas, constituyendo una importante carga térmica que es necesario atenuar durante períodos muy cálidos y aprovechar en períodos invernales. Se registraron diferencias térmicas de hasta $20^{\circ} \mathrm{C}$ entre superficies adyacentes de igual constitución, por la sola incidencia de la radiación solar en una zona y no en otra).

\section{CONCLUSIONES Y PERSPECTIVAS}

La termografía constituye una herramienta muy útil para un conocimiento cualitativo del comportamiento de la envolvente edilicia, como complemento de las otras herramientas e instrumentos aplicados (monitoreos, simulaciones dinámicas y verificaciones normativas), que apuntan a una interpretación más cuantitativa de la problemática. Se infiere, mediante la interpretación de las imágenes termográficas, que factores de diseño en los que resulta muy sencillo incidir sin ningún costo económico - como la elección del color de una superficie de la envolvente constructiva edilicia- tienen influencia importante en las temperaturas de dichas superficies (y por ende, de los espacios interiores que ellas delimitan), por lo que resultaría fundamental tenerlos en cuenta en el proceso proyectual. Otro factor de diseño, relacionado con el grado de exposición de los volúmenes y sus diferentes caras a la radiación solar, también repercute significativamente en las temperaturas superficiales de las envolventes y de los espacios que ellas albergan, así como la cantidad de tiempo y franja horaria en que dicha exposición tiene lugar, por lo que resulta necesario estudiarlo cuidadosamente para la regulación de las cargas térmicas (ganancias y pérdidas). En función de los resultados obtenidos, se hacen necesarias propuestas de mejoramiento de las envolventes de los sectores de aulas del edificio de la FAU - UNNE (especialmente del bloque nuevo), que optimicen su desempeño térmico, sobre todo en la época cálida, y que contribuyan a la reducción del consumo eléctrico para climatización artificial, a la vez que resulten transferibles al mejoramiento de las condiciones de otros edificios del campus UNNE. Entre dichas mejoras podrían incluirse la reducción de puentes térmicos y de pérdidas por carpinterías en general y el aumento de resistencia térmica del conjunto envolvente, así como la provisión de dispositivos de control de incidencia de radiación solar, especialmente en aberturas.

Los resultados obtenidos mediante estos estudios experimentales configuran un marco instrumental, que aporta herramientas de análisis de la eficiencia energético-ambiental del sector edilicio regional. 


\section{BIBLIOGRAFÍA}

ALÍAS, H. M. et al. (2011). Monitoreo térmico de aulas de la Facultad de Arquitectura de la UNNE (Resistencia, Chaco) en días de invierno y condiciones reales de ocupación. Avances en Energías Renovables y Medio Ambiente (AVERMA), Vol. 15, pp. 07.81 a 07.89. Argentina. ISSN $0329-5184$. CORONEL, C. A. et al. (2011). Evaluación energética del edificio sede de la Facultad de Arquitectura y Urbanismo - UNNE (Resistencia - Chaco - Argentina) con la herramienta informática "ECOTECT". IV Congreso Regional de Tecnología en Arquitectura. (CRETA). Facultad de Arquitectura y Urbanismo de la Universidad Nacional del Nordeste. Resistencia, Chaco, Argentina.

FLORES LARSEN, S. y HONGN, M. (2012). Termografía infrarroja en la edificación: aplicaciones cualitativas. Avances en Energías Renovables y Medio Ambiente (AVERMA), Vol. 16, pp. 08.25 a 08.32. Argentina. ISSN 0329-5184.

FLUKE (2010). "Ti9, Ti10, Ti25, TiRx, TiR and TiR1. Thermal Imagers. Manual de uso". Versión en español. Fluke Corporation. USA.

INSTITUTO ARGENTINO DE RACIONALIZACIÓN DE MATERIALES (IRAM). Normas Técnicas Argentinas: 11601: 1996; 11603: 1996; 11605: 1996; 11625: 2000; 11630:2000; 11507-1:2001; 11507-4:2010. Buenos Aires, Argentina.

Agradecimiento: al Prof. Ing. RUBÉN SPOTORNO, docente e investigador de la Universidad Tecnológica Nacional (UTN), Delegación Resistencia (Chaco), por la puesta a disposición del procesador térmico de imágenes. 